\title{
Protective Role Of Proanthocyanidin Against Carbon Tetrachloride Induced Toxicity In Irradiated Rats
}

\author{
Mona A. El-Gawish, Amira T. Ebrahim*, Fatma A. Eid* \\ National Center for Radiation Research and Technology-Atomic Energy \\ Authority. Zoology Department, Faculty of Science, \\ Al-Azhar University*.
}

\begin{abstract}
The hepatic injury induced by carbon tetrachloride $\left(\mathrm{CCl}_{4}\right)$ as well as gamma-irradiation has taken most attention. Prevention is one of the essential ways of controlling this toxicity and the use of natural plant compounds as grape seed extract can be considered as one of the most significant elements in this prevention. The present study is also designed to evaluate the hepatoprotective effects of grape seed extract $(100 \mathrm{mg} / \mathrm{kg} \mathrm{B}$.wt daily) against the toxic effect of $\mathrm{CCl}_{4}(0.3 \mathrm{ml} / \mathrm{kg} \mathrm{B}$.wt twice weekly for 8 weeks $)$ and/ or fractionated doses of $2 \mathrm{~Gy} \gamma$-radiation day after day up to $10 \mathrm{~Gy}$ in male rats.

Results obtained could be summarized as follows: Combined treatments of $\mathrm{CCl}_{4}$ and $\gamma$ radiation induced a significant increase in malondialdehyde (MDA) level, and decreased level of reduced glutathione (GSH). It also increased serum enzymes aspartate transferase (AST), alanine transferase (ALT), a olkaline phosphatase (ALP) and gamma - glutamyl transpeptidase $(\gamma$-GT) activities and decreased $\mathrm{Hb} \%$, RBCs, WBCs and platelets count. Proanthocyanidin administration improved the significant increase in MDA level and ameliorated serum enzymes as well as improved the decreased level of GSH content of irradiated rats or those treated with $\mathrm{CCl}_{4}$. It also could normalize the blood constituents $\mathrm{Hb} \%, \mathrm{RBCs}$, WBCs and platelets count. The data of the present study declared that proanthocyanidin is bioavailable, potent free radical scavenger and exhibits antioxidant properties against $\mathrm{CCl}_{4}$ and gamma-irradiation induced hepatic injury.
\end{abstract}

\section{Introduction}

Virtually occupational exposures to toxic concentrations of carbon-tetrachloride vapours are possible during industrial use of the chemicals (NCI, 1985). It has been reported that oral exposure produced marked central nervous system depression and remarkable liver injury (Piyachaturawt et al., 1995).

Injury produced by $\mathrm{CCl}_{4}$ seems to be mediated by reactive metabolite-trichloromethyl free radical $\left(\mathrm{CCl}_{3}\right)$ formed by hemolytic cleavage of trichloromethyl peroxy free radical $\left(\mathrm{Cl}_{3} \mathrm{COO}\right)$ formed by the reaction of $\mathrm{CCl}_{3}$ with $\mathrm{O}_{2}$ (Slater, 1982), which attach enoic fatty acids in the membranes of endoplasmic reticulum, leading to secondary free radicals, which are subjected to attack by oxygen, and subsequent process, termed lipid peroxidation, which produces damage to membranes and enzymes (Poli et al., 1989).

The beneficial properties of flavonoids, including proanthocyanidins, have been extensively researched (Murray and Pizzorno, 1999). In addition to their antioxidant and free radical scavenging activity (Faria et al., 2006), proanthocyanidins found in grape seed extract have been reported to have antibacterial, anticarcinogenic, antiviral, anti-allergic, anti-inflammatory effects (Blazso et al., 1994) vasodilatory actions (Bagchi et al., 1998), antimutagenic agents, provide cardioprotection by maintaining vascular permeability 
(Bagchi et al., 2003) and the maintainance of DNA integrity (Bagchi et al., 1998).

\section{Material and Methods}

\section{Animals:}

A total of 120 male Albino rats weighing 130-140 gm were used as experimental animals. The rats were housed 6 animals/ cage with controlled air, temperature and relative humidity and maintained on standard cube pellets with free access to water. The diet consisted of not less than $20 \%$ protein, $5 \%$ fibers, $3 \%$ fats, $6.5 \%$ ash and supplied with vitamins and minerals mixture.

\section{Gamma-irradiation procedure:}

Irradiation process was performed using Gamma Cell-40 achieved by Egypt's National Center for Radiation Research and Technology (NCRRT), Cairo. The dose rate was $0.66 \mathrm{~Gy} / \mathrm{min}$. at the time of experimentation.

\section{Chemicals:}

Grape Seed extract (Proanthocyanidin) was purchased from Natur's Purest (West Los Angeles, CA 90025). it was dissolved in DMSO and diluted to the appropriate concentration by sterilized saline solution. Carbon-tetrach-lorid was diluted to the appropriate concentration by olive oil.

\section{Animal groups:}

The experimental animals were divided into 8 groups (each group contains 15 rats) as follows:

Group1: Untreated control rats.

Group2: Animals were exposed to fractionated doses of $\gamma$-irradiation (2Gy ,day after day, up to $10 \mathrm{~Gy}$ ).

Group3:Animals were injected intraperitoneally (i.p.) with $\mathrm{CCl}_{4}$ alone $(0.3 \mathrm{ml} / \mathrm{kg} \mathrm{B} . w \mathrm{t})$ twice weekly for 8 weeks (Yasuda et al ., 2000).

Group4: Animals were first treated with $\mathrm{CCl}_{4}$ as described in group $3(0.3 \mathrm{ml} / \mathrm{kg}$ B.wt.) and then exposed to fractionated doses of $\gamma$-irradiation (2Gy, day after day, up to $10 \mathrm{~Gy}$ ).
Group5: Animals were given orally a natural antioxidant (Proanthocyanidine) daily for one week at a dose of $100 \mathrm{mg} / \mathrm{kg}$ B.wt (Bagchi et al., 2001).

Group6: Animals were first given proanthocyanidin orally (daily for one week at a dose of $100 \mathrm{mg} / \mathrm{kg} \mathrm{B.wt),} \mathrm{then} \mathrm{exposed}$ to fractionated doses of $\gamma$-irradiation (2Gy day after day up to $10 \mathrm{~Gy}$ ).

Group7: Animals were given proanthocyanidin orally (daily for one week at a dose of $100 \mathrm{mg} / \mathrm{kg} \mathrm{B.wt}$ ), before the i.p. injection with $\mathrm{CCl}_{4}$ and continuing for another 8 weeks parallel with the injection of $\mathrm{CCl}_{4}$

( $0.3 \mathrm{ml} / \mathrm{kg}$ B.wt.)

Group8: Animals were given proanthocyanidin orally (daily for one week at a dose of $100 \mathrm{mg} / \mathrm{kg} \mathrm{B.wt),} \mathrm{before} \mathrm{the}$ injection with $\mathrm{CCl}_{4}$ and continuing for another 8 weeks parallel with the injection of $\mathrm{CCl}_{4} \quad(0.3 \mathrm{mg} / \mathrm{kg} \quad$ B.wt $)$ followed by exposure to fractionated doses of $\gamma$ irradiation (2Gy, day after day, up to 10 Gy). All experimental groups were sacrificed after one day, 7 days, and 14 days post treatment or irradiation.

\section{Biochemical studies:}

Animals were sacrificed by slight ether anesthesia. A portion of blood samples were immediately collected and used for the determination of reduced glutathione (GSH) level as described by Beutler, (1963) as well as WBCs, RBCs, $\mathrm{Hb} \%$, and thrombocyte count were estimated according to Dacie and Lewis (1991). Another portion of blood was taken for the separation of serum for the determination of malonedialdehyde (MDA) according to the method of Yoshioka et al., (1979). AST, ALT, ALP and $\gamma$-GT were measured as described by Reitman and Frankel (1957), John and Bauer (1982) and Szasz (1969) respectively. The data were statistically analyzed following the student's test $(t)$ (Snedecor and Cochran 1980).

\section{Results}

Exposure of rats to whole body $\gamma$ irradiation or those received $\mathrm{CCl}_{4}$ induced 
significant increases $(\mathrm{P}<0.05,0.01)$ in the level of serum ALP activity all over the experimental periods as compared to control group. Additionally irradiated rats received $\mathrm{CCl}_{4}$ exhibited highly significant increases in serum ALP activity reached 102.58, 55.94 and $18.68 \%$ at the investigated periods respectively (Fig.1).

On the other hand, pretreatment of irradiated rats or those received $\mathrm{CCl}_{4}$ with proanthocyanidin induced a great amelioration in serum ALP activity in both groups. This was evident as the level of serum ALP activity was restored and recorded nonsignificant changes as compared to control group after 7 and 14 days of treatment.

Significant increase $(P<0.05-0.001)$ in serum $\gamma$-GT activity was recorded due to whole body $\gamma$ - irradiation and / or treatment of rats with $\mathrm{CCl}_{4}$ as compared to control group (Fig.2). Pretreatment of irradiated rats with proanthocyanidin induced a limited improvement in serum $\gamma$-GT activity at 1,7 days post-irradiation, while a great amelioration was observed in serum $\gamma$-GT after 14 days post-irradiation, recording non-significant change as compared to control group. In addition, the antioxidant proanthocyanidin could restore the level of serum $\gamma$-GT activity in rats exposed to $\gamma$-irradiation and received $\mathrm{CCl} 4$. This was evident as the level of serum $\gamma$-GT activity recorded non-significant changes as compared to control group after 7 and 14 days of treatment as shown in Fig.(2).

The data obtained in Fig. ( $3 \& 4)$ revealed highly significant increases $(\mathrm{P}<$ $0.01-0.001)$ in serum ALT and AST respectively in both groups of animals either exposed to fractionated doses of $\gamma$ radiation or received $\mathrm{CCl}_{4}$ or those received both treatments all over the experimental periods. Administration of proanthocyanidin to irradiated rats or those received $\mathrm{CCl}_{4}$ induced a great amelioration in serum ALT activity in both groups. In addition, pretreatment of irradiated rats with $\mathrm{CCl}_{4}$ and proanthocyanidin improved the significant increase in serum ALT activity in respect to the irradiated and $\mathrm{CCl}_{4}$ treated groups even though its level was still higher than the control group (Fig.3) . In addition, proanthocyanidin succeded in restoring the level of serum AST activity in rats exposed to $\gamma$ - irradiation and received $\mathrm{CCl}_{4}$. This was manifested as the level of serum AST activity recorded non-significant changes as compared to control group after 14 days of treatment (Fig.4).

Significant decrease $(\mathrm{P}<0.05,0.001)$ in the levels of total leucocyte, erythrocytes count and $\mathrm{Hb} \%$ was recorded in rats exposed to radiation or received $\mathrm{CCl}_{4}$ or treated with both of them as illustrated in Fig. (5, $6 \& 7)$ respectively.

On the other hand, pretreatment of irradiated rats with proanthocyanidin induced a great amelioration in total leucocytes count especially after 14 day of treatment (Fig. 5).

In addition, pretreatment with proanthocyanidin to rats exposed to $\gamma$ - irradiation and received $\mathrm{CCl}_{4}$ induced non-significant change in total erythrocytes count throughout the experimental intervals reflecting the protective effect of proanthocyanidin (Fig. 6).

Furthermore, administration of proanthocyanidin could restore the level of blood $\mathrm{Hb} \%$ in rats exposed to $\gamma$-irradiation and received $\mathrm{CCl}_{4}$ as manifested by a nonsignificant changes in $\mathrm{Hb} \%$ compared to control values after 1,7 and 14 days of treatment (Fig. 7).

Thrombocyte counts in the investigated groups approximately matched the changes occurred in leucocyte, erythrocytes count and $\mathrm{Hb} \%$ all over the experimental periods (Fig. 8).

Figure (9) demonstrate that rats exposed to whole body $\gamma$ - irradiation or received $\mathrm{CCl}_{4}$ induced a significant increase $(\mathrm{P}<0.05-0.001)$ in the level of MDA all over the experimental periods as compared to control group. On the other hand, pretreatment of irradiated rats or those received $\mathrm{CCl}_{4}$ with proanthocyanidin induced a great amelioration in MDA in both groups. In addition, proanthocyanidin succeded in restoring the level of MDA in rats exposed to $\gamma$ - irradiation and received $\mathrm{CCl}_{4}$. This was evident as the level of MDA recorded non-significant changes as compared to control group after 14 day of treatment. 
Exposure of rats to whole body $\gamma$ irradiation or treated with $\mathrm{CCl}_{4}$ induced a significant decrease $(\mathrm{P}<0.01-0.001)$ in the level of blood GSH content all over the experimental periods as compared to control group (Fig. 10).

Irradiated rats received $\mathrm{CCl}_{4}$ exhibited highly significant decreases in blood GSH all over the experimental periods reflecting the synergestic effects of both treatments on GSH level.

Non-significant change in blood GSH was observed in rats received the proanthocyanidin alone. On the other hand, pretreatment of irradiated rats or those received $\mathrm{CCl}_{4}$ with proanthocyanidin induced a great amelioration in blood GSH in both groups. In addition, the proanthocyanidin improved the level of blood GSH in rats exposed to $\gamma$-irradiation and received $\mathrm{CCl}_{4}$. This was evident as the level of $\mathrm{GSH}$ recorded non-significant changes as compared to control group after 7 and 14 days of treatment.

Non-significant changes in the investigated parameters were observed in rats received the proanthocyanidin alone.

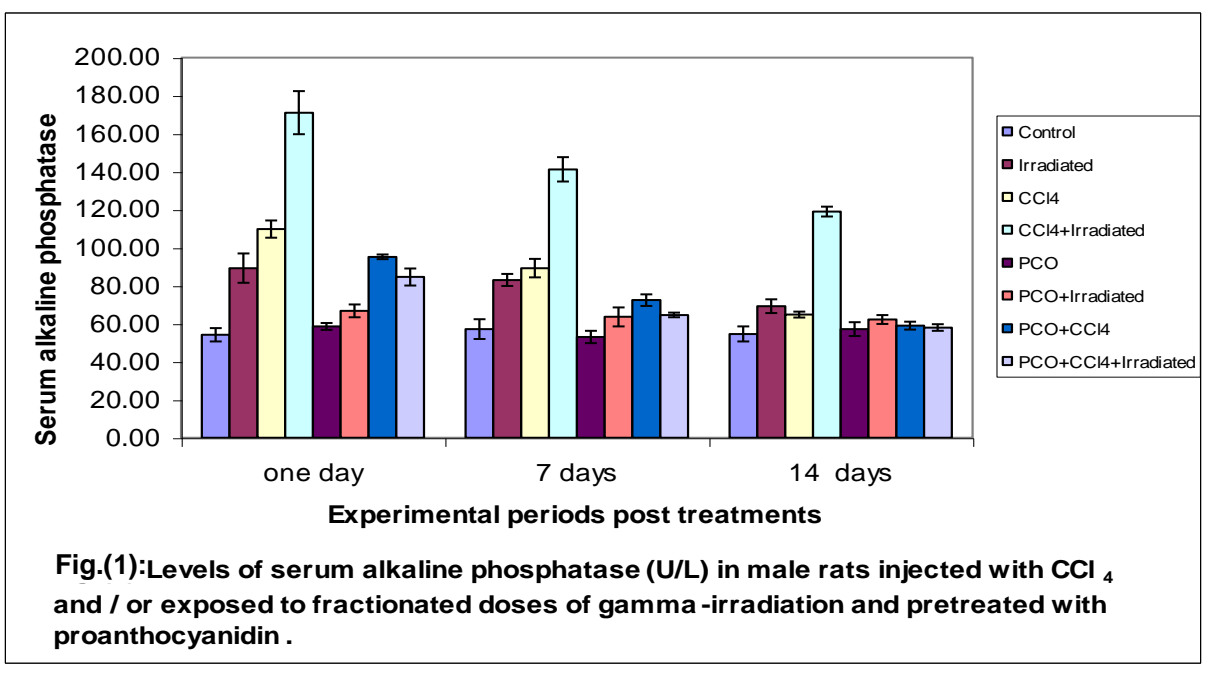



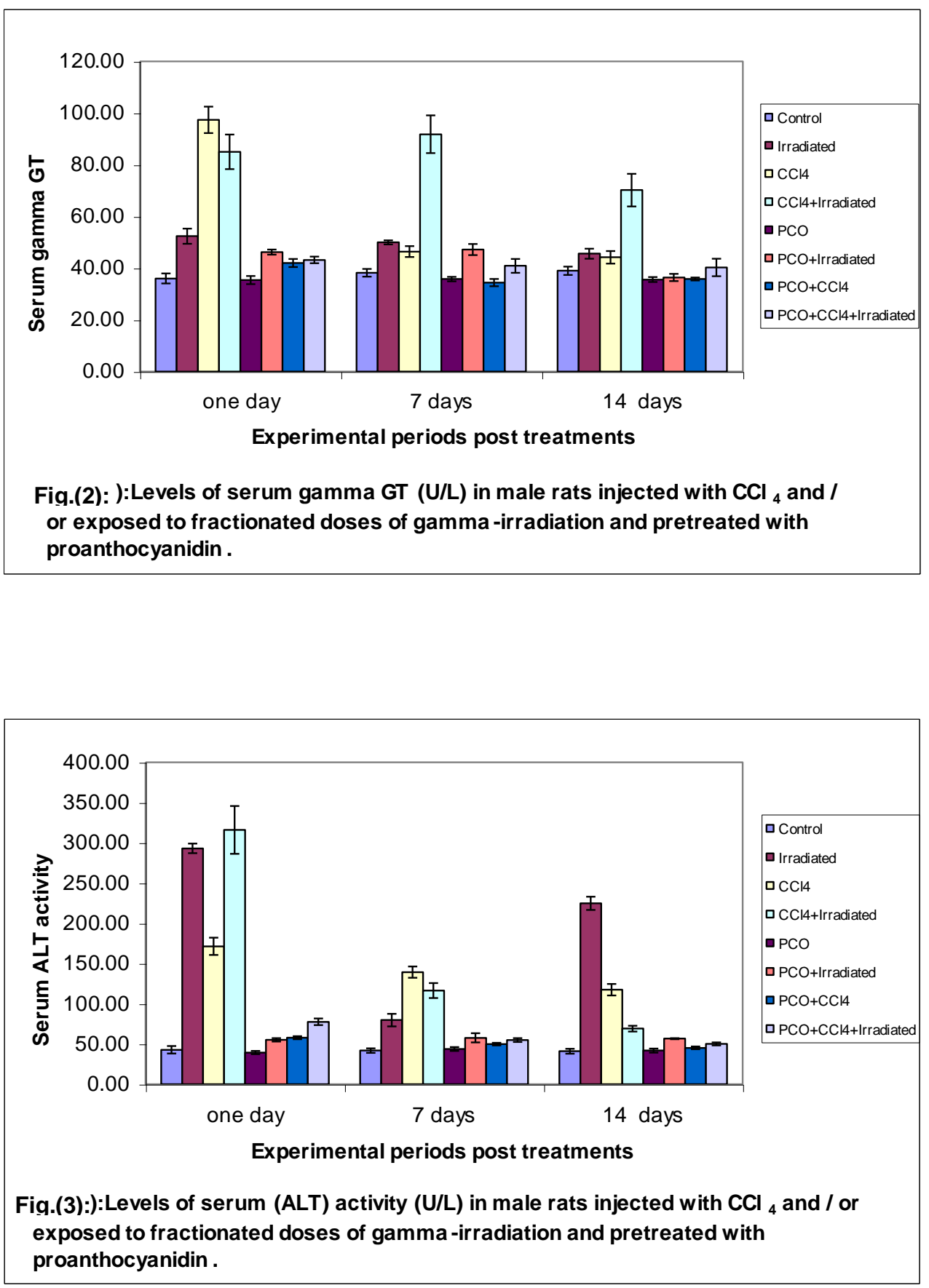

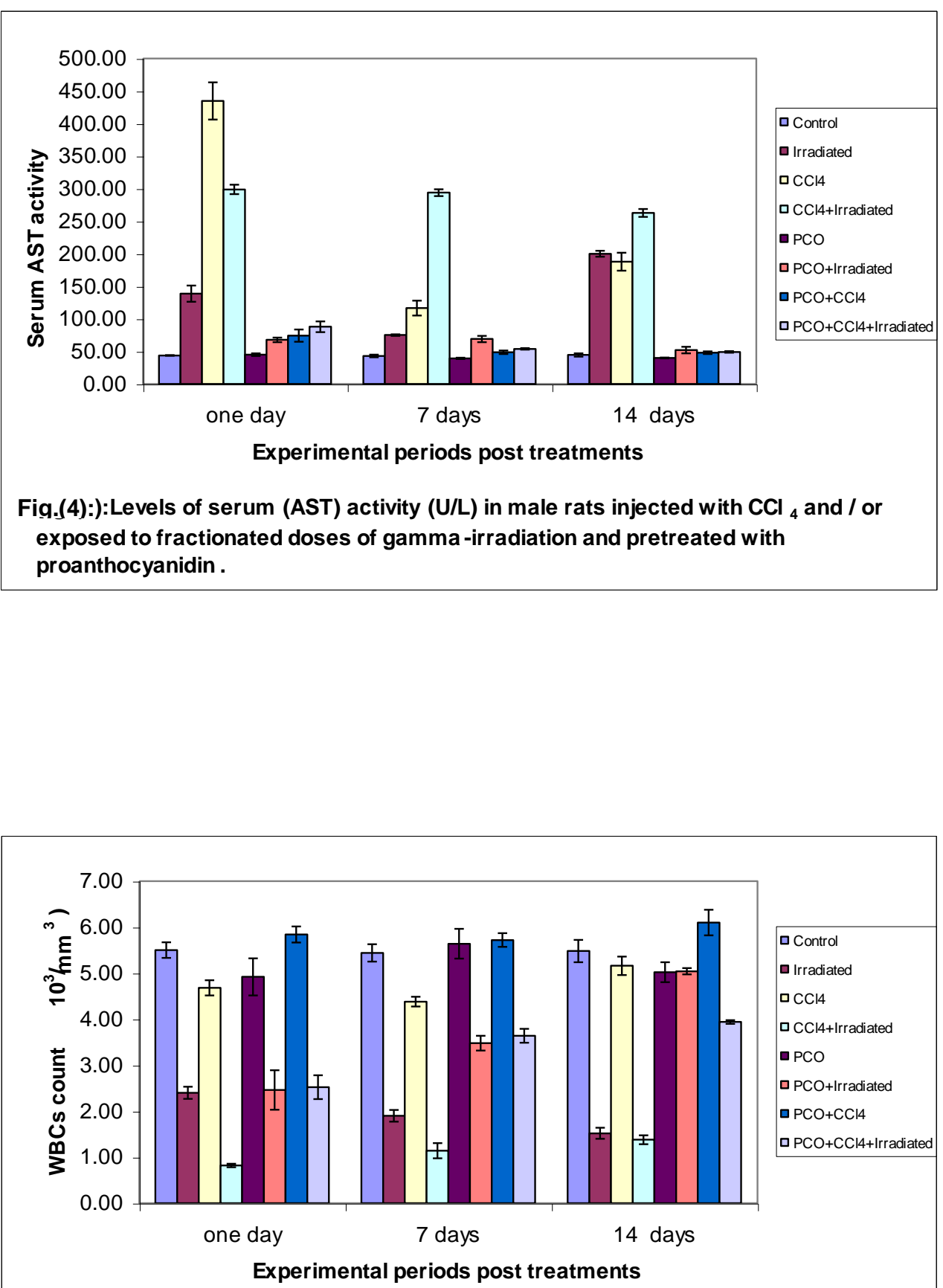

Fig.(5):): Total leucocytic (WBCs) count ( $X 10^{3} / \mathrm{mm}^{3}$ ) in male rats injected with $\mathrm{CCl}_{4}$ and / or exposed to fractionated doses of gamma -irradiation and pretreated with proanthocyanidin . 

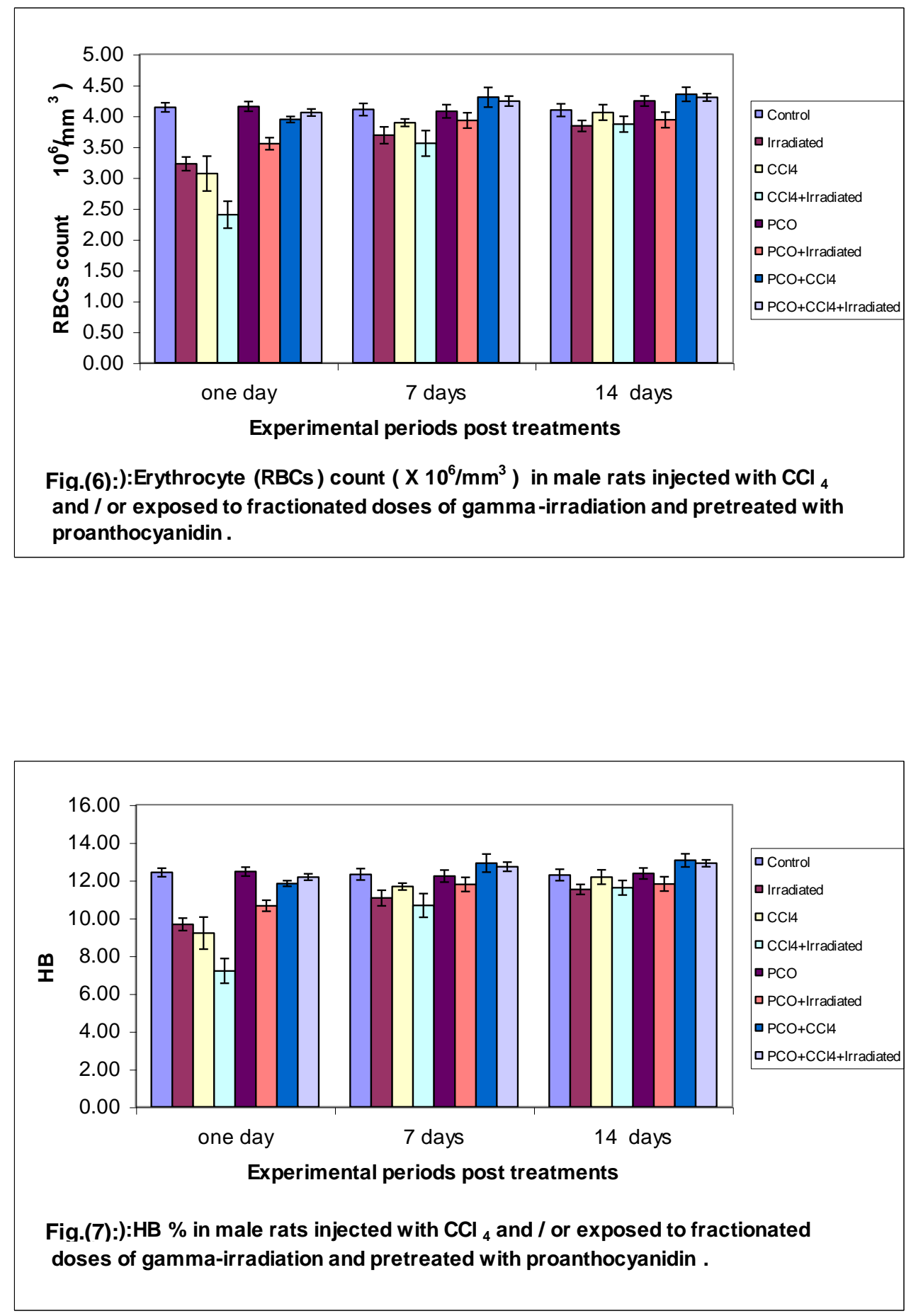
Protective Role Of Proanthocyanidin Against Carbon
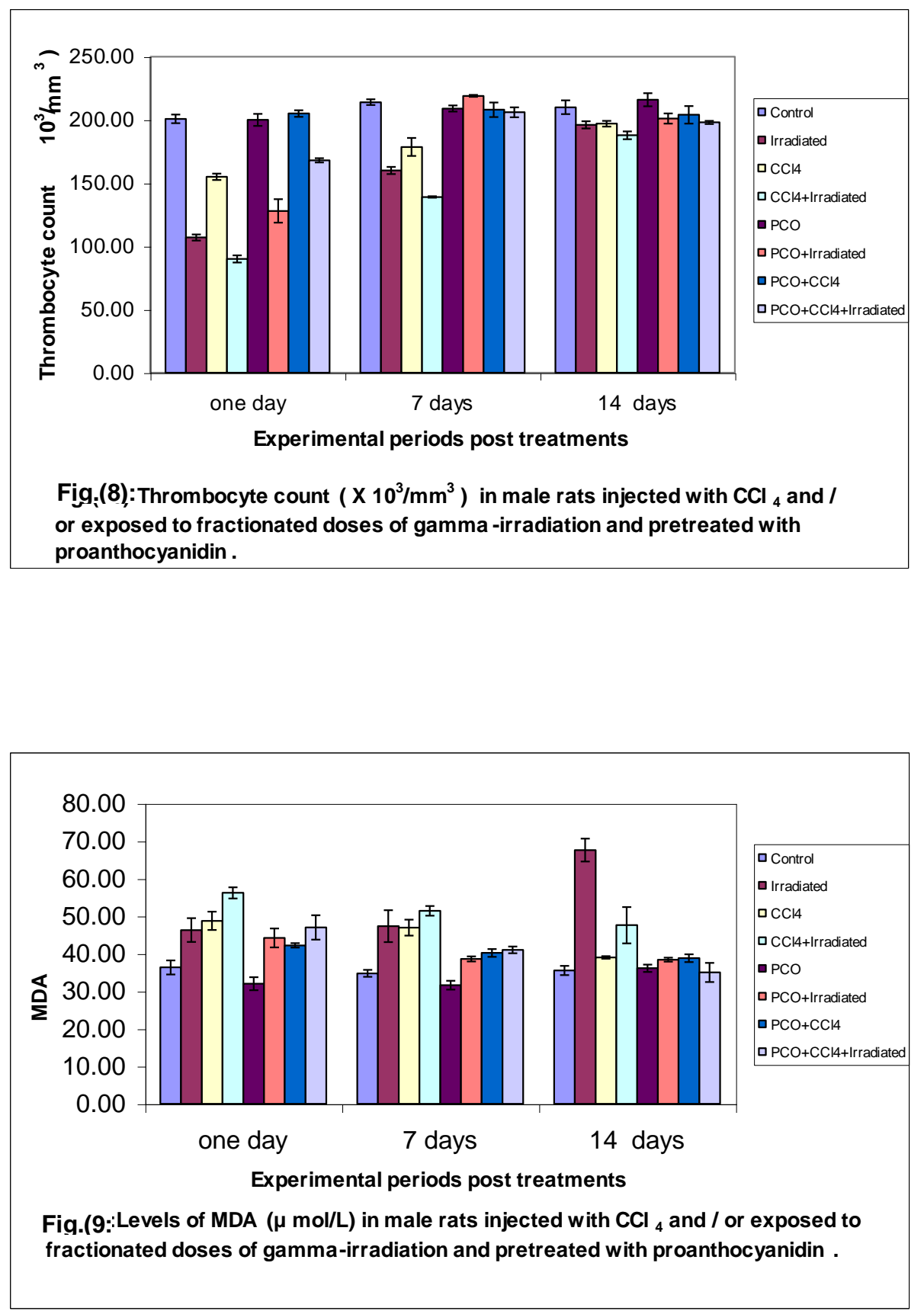


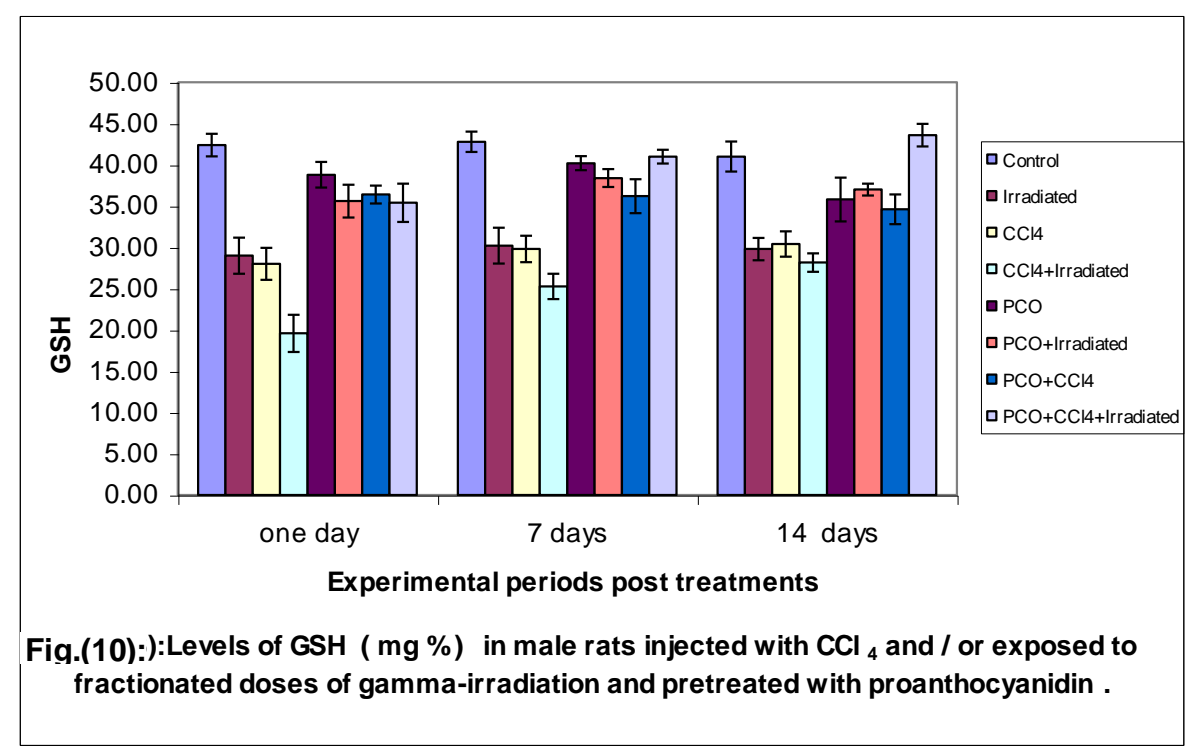

\section{Discussion}

The data of the present study revealed a disturbance in serum enzymes AST, ALT, $\gamma$-GT and ALP activities. These results run in agreement with the results of many authors (Abu-Ghadeer and El-Gawish, 1996; Abdel-Fattah and Saad El-Deen, 1997 and Kamat et al., 2000). The changes in transaminases may attributed to the hepatocellular injury as a result of irradiation exposure, which in turn led to release of the enzymes from the hepatic cells into the blood stream (Weiss and Landauer 2003); Abou-Seif et al., 2003).

Data of the present study have indicated that whole body $\gamma$-irradiation resulted in disorders in the haematological constituents as manifested by drop in leucocyte, erythrocyte, $\mathrm{Hb} \%$ and thrombocyte counts. Similar observations were obtained by Hassan et al., (1994) and AbuGhadeer and El-Gawish, (1996). The reduction in total leucocytic, erythrocyte, and thrombocyte count after radiation exposure observed in this study may be due to mitotic inhibition of the bone marrow precursors. Since, the basic designation of the bone marrow is the production of mature highly differentiated blood cells, accordingly, radiation exposure might depress the ability of bone marrow to produce its cells (Martin and Harbison,
1986). As the number of stem cells in the bone marrow decreases, a corresponding decrease would be exhibited in the number of the respective mature circulating cells. The radiosensitivity of the blood forming tissues was recognized early in the history of radiobiology. In human, blood platelets and neutrophils count decreased after local radiotherapy (Mohiuddin et al., 1996). This could be attributed to direct destruction of the mature circulating cells, loss of cells from circulation by haemorrhage or leakage through capillary wall, and loss of production of cells. Since the blood cells have a definite life span, they must be constantly renewed by cell production in the haemopoietic tissues. If such cell population is inhibited, replacement of circulating cells will not occur. So, depressed haematopoiesis is a major factor in decreasing the numbers of circulating cells.

Two mechanisms were suggested to explain the reduction in $\mathrm{Hb}$ concentration due to irradiation. Firstly, blockage the incorporation of iron into $\mathrm{Hb}$ due to disturbance in the biogeneration structure of the $\mathrm{Hb}$ molecule as evidenced by pronounced hyper-ferraemia post-irradiation. Second, oxidation of $\mathrm{Hb}$ iron causing loss of the biological structure and activity of $\mathrm{Hb}$ molecule (Nunia and Goyal, 2004). 
The results of the present study showed that whole body $\gamma$-irradiation seriously stimulated lipid peroxidation production. This was evident from the highly significant increase in MDA as one of the main end products of lipid peroxidation. The recorded increase in MDA could be explained on the basis of that ionizing radiation induced lipid peroxidation through the production of active oxygen species, which attack the polyunsaturated fatty acids of the phospholipids of cell membrane (Gatsko et al., 1990).

In the view of the data obtained in the present work, there was a significant decrease in blood glutathione. Such decrease was in accordance with the data reported by EL-Gawish et al. (1997 \& 2000) and Abou-seif et al. (2003), Badr-El-Din (2003). The recorded decrease in the reduced GSH could be attributed to its conversion to the oxidized form with minimal chance to be recycled to the reduced form again due to inhibition of GSH reductase (Kergonou et al., 1986). Jiangui and Sun (1993), found a correlation between the increase of lipoperoxide in irradiated mice and the decrease of the antioxidant defense system. This decrease in the scavenging system located extracellularly and inracellulary gives rise to excessive production of free radicals.

The data of the present study revealed that administration of $\mathrm{CCl}_{4}$ induced similar changes in the investigated parame-ters to those exposed to $\gamma$-radiation. Injury produced by $\mathrm{CCl}_{4}$ seems to be mediated by reactive metabolite-trichloromethyl free radical $\left(\mathrm{CCl}_{3}\right)$ formed by the hemolytic cleavage of trichloromethylperoxy free radical $\left(\mathrm{Cl}_{3} \mathrm{COO}\right)$ formed by the reaction of $\mathrm{CCl}_{3}$ with $\mathrm{O}_{2}$ (Slater, 1982). This biotransformation is catalyzed by a cytochrome P450-dependent monooxygenase to yield trichloromethyl and chlorine free radicals. The trichloromethyl free radical is then thought to attach enoic fatty acids in the membranes of the endoplasmic reticulum, leading to secondary free radicals within the fatty acids, which is subjected to attack by oxygen, and the subsequent process, which is termed lipid peroxidation, produces damage to membranes and enzymes (Poli , 1989). Thus the toxicity of $\mathrm{CCl}_{4}$ depends on the cleavage of carbonchloride bond to generate trichloromethyle free radical $\left(\mathrm{CCl}_{3}\right)$ ( Lee et al., 2004 ). Consequently, the $\mathrm{CCl}_{4}$-derived free radicals can initiate a process of autocatalytic lipid peroxidation by attacking the methyl bridges of unsaturated fatty side-chains of microsomal lipids (Yan et al., 2003).

The decline in glutathione content together with increased lipid peroxidation following $\mathrm{CCl}_{4}$ administration were reported by Kus et al., (2004); Shukla et al., (2004) and Valcheva et al., (2004).

$\mathrm{CCl}_{4}$ treatment generates free radicals that trigger a cascade of events resulting in liver dysfunction (Luo et al., 2004 and Aziz et al., 2005) as reflected by significant increase in serum AST, ALT, ALP and $\gamma$ GT activities (Gao et al., 2004; Ha et al., 2005),

The data of the present study proved that oral administration of proanthocyanidin ameliorated all the investigated parameters in animals exposed to fractionated doses of gamma-irradiation or treated with $\mathrm{CCl}_{4}$. Our results are in agreement with Bagchi et al., (1998), Ray et al.(2000), Abou seif et al., (2003) and Weiss and Landauer (2003).

Proanthocyanidins, a group of polyphenolic bioflavonoids, have been reported to exhibit a wide range of biological, pharmacological and chemoprotective properties against oxygen free radicals (Bagchi et al., 1997, 2002 and Ray et al., 2000).

It has been reported by Bagchi et al., (1999), that proanthocyanidin provided significant protection against acute and chronic stress-induced gastrointestinal and hepatic oxidative injury as demonstrated by reduced lipid peroxidation, DNA damage and membrane microviscosity.

Grape seed extracts (GSE) contain a total of $92 \%$ to $95 \%$ the gallic esters of proanthocyanidins (PCO) (Veluri et al., 2006). These compounds are the most active free radical scavenging PCOs (Bagchi et al., 1998). GSE recycles and significantly extends the lifetime of vitamin $\mathrm{C}$ and potentiates vitamin $\mathrm{E}$, and thereby creates a more powerful, synergistic 
antioxidant defense in the body. This is important because vitamins $\mathrm{C}$ and $\mathrm{E}$ are key players in the body's protective antioxidant army, and by increasing the activity of vitamins $\mathrm{C}$ and $\mathrm{E}$ in the body, GSE helps the body to maintain its antioxidant defenses (Masquelier, 1996).

Grape seed extract showed potent antioxidant activity by trapping free radicals and antioxidative fats (hydroxyl and lipid free radicals, free iron molecules, and lipid peroxides), delaying fat oxidation, inhibiting the major substance responsible for generating oxygen-derived free radicals (xanthine oxidase) and reducing the concentration of $\mathrm{H}_{2} \mathrm{O}_{2}$ produced by oxidative stress (Sugisawa et al., 2004).

Wang et al., (1999) reported that proanthocyanidin could reduce the aggregation of platelets, increase the red blood cell pliability, decrease blood viscos-ity and increase fibrinolytic activity. In addition, proanthocyanidin improves the oxygen carrying capacity of blood, increases the strength and elasticity of blood vessel wall by binding with collagen. Flavonoids in general and proanthocy-anidins in particular are free of side-effects, since they are water soluble, any excess proanthocyanidins are excreted via sweat or urine. So grape seed extract can be used safely and effectively in conjunction with other antioxidants plus the minerals (Yamakoshi et al., 2002). Proanthocyanidin from grape seeds have been reported to show various beneficial properties including hepatoprotective effects as well as modulatory role on age-related oxidative DNA damage (Balu et al., 2006).

\section{References}

1. Abdel-Fattah, K.I. and Saad El-Deen, A. (1997): "Physiological responses of rat plasma proteins and protein fractions and their relationship as induced by cumulative doses of whole body gamma-irradiation of albino rat". J. Egypt. Ger. Soc. Zool.; 22(A): 139-151.

2. Abou-Seif, M.A.; El-Naggar, M.M.; ElFar, M.; Ramadan M.; and Salah, N. (2003): "Preventation of biochemical changes in gamma-irradiated rats by some metal complexes". Clin. Chem. Lab. Med.; 41(7): 926-933.

3. Abu-Ghadeer, A.R.M. and El-Gawish, M.A.M. (1996): Role of lipoic acid in the control of radiation induced injuries in rats .J. Egypt. Ger. Soc. Zool.; 21(A) 63-79.

4. Aziz, T.A.; Aziz, M.A.; Fouad, H.H.; Rashed, L.A.; Salama, H.; Abd-Alla, S. Wehab, M.A. and Ahmed, T. (2005): "Interferon-alpha gene therapy prevents aflatoxin and carbon- tetrachloride promoted hepatic carcinogenesis in rats". Int. J. Mol. Med.;15(1):21-26.

5. Badr-El-Din (2003): "Protective role of Sanumgerman against gamma-irradiationinduced oxidative stress in Ehrlich Carcinoma - bearing mice".Egypt. J. Rad. Applic.; 16 (2), 231-256.

6. Bagchi, D.; Krohn, R.L. and Bagchi, M. (1997): "Oxygen free radical scavenging abilities of vitamins $\mathrm{C}$ and $\mathrm{E}$, and a grape seed proanthocyanidin extract in vitro". Res. Commun. Mol. Pathol. Pharmacol. ; 95:179-189.

7. Bagchi, D.; Garg, A. and Krohn, R. (1998): "Protective effects of grape seed proanthocyanidins and selected antioxidants against TPA-induced hepatic and brain lipid peroxidation and DNA fragmentation, and peritoneal macrophage activation in mice". Gen. Pharmacol. ;30: 771-776.

8. Bagchi, M.; Williams, C.B.; Milnes, M.; Balmoori, J. Ye, X.; Bagchi, D. and Stohs, S.J. ( 1999). "Acute and chronic stress-induced oxidative gastric injury in rats, and protection by a novel IH636 grape seed proanthocyanidin extract (GSPE)", $5^{\text {th }}$ Annual Meeting of the Oxygen Society, Washington, D.C., Abstract published in Free Radical Biology \& Medicine (Supplement), Abstract 235, pp. S83.

9. Bagchi, D.; Ray, S.D.; Patel, D. and Bagchi, M. (2001): "Protection against drug- and chemical-induced multiorgan toxicity by a novel IH636 grape seed proanthocyanidin extract". Drugs Exp.Clin. Res.;27(1): 3-15.

10. Bagchi, D.; Ray, S.D.; Bagchi, M.; Preuss, H.G. and Stohs, S.J. (2002): "Mechanistic pathways of antioxidant cytoprotection by a novel IH636 grape seed proanthocyanidin extract". Indian. J. Exp. Biol.; 40(6): 717-726.

11. Bagchi, D.; Sen, C.K.; Ray, S.D.; Das, D.K.; Bagchi, M.; Preuss, H.G. and Vinson, J.A. (2003): "Molecular mechanisms of cardioprotection by a novel grape 
seed proanthocyanidin extract”. Mutat. Res.; 523: 87- 97.

12. Balu M, Sangeetha P, Murali G, and Panneerselvam C. (2006): Modulatory role of grape seed extract on age-related oxidative DNA damage in central nervous system of rats. Brain Res Bull. 15;68(6):469-73.

13. Beutler. E.; Duron, O. and Kelly, B.M. (1963): "Improved method of the determination of blood glutathione". J. Lab. \& Clin. Med.; 61(5): 882-888.

14. Blazsó, G.; Gábor, M.; Sibbel, R. and Rohdewald, P. (1994): "Anti-inflammatory and super-oxide radical scavenging activities of a procyanidins containing extract from the bark of Pinus pinaster Sol. and its fractions". Pharm. Pharmacol. Lett. (3): 217-220.

15. Dacie, J.V. and Lewis, S.M. (1991): "Basic practical haematology. In: practical haematology": 7th ed., the English Languages Book Society and Churchill Livingstonne., 37 - 58.

16. El-Gawish, M.A.M.; Abady, M.M. and Said, O.Z. (1997): "Potential prophylactic role of ginseng against biochemical hazards of whole body gamma-irradiation in albino rats.” Egypt. J. Med. Sci.; 18(2): 583-598.

17. El-Gawish, M.A.; Mahdy, E.M.E.; Hafez, M.N. and El-Hadidy, M. E.A. (2000): "Protective effects of natural isoflavone On 1,2-dimethylhydrazine carcino-genesis in irradiated rats". Cancer Molecular Biology, 7(4):1527-1543.

18. Faria A, Calhau C, de Freitas V, and Mateus N. (2006): Procyanidins as antioxidants and tumor cell growth modulators. J Agric Food Chem. 54(6):2392-7.

19. Gao, J; Tang, X.; Dou, H.; Fan, Y.; Zhao, X. and Xu, Q. (2004): "Hepatoprotective activity of Terminalia catappa L. leaves and its two triterpenoids. J. Pharm. Pharmacol.".; 56(11):1449-1455.

20. Gatsko, G.G.; Mazhul, L.M.; Shablinskaya, O.V. and Volykhina, V.E. (1990): "The influence of ionizing radiation on lipid peroxidation in rat blood". Radiobiology; 30 (3): 413 - 415.

21. Ha, K.T.; Yoon, S.J.; Choi, D.Y.; Kim, D.W.; Kim, J.K. and Kim, C.H. (2005): "Protective effect of Lycium chinense fruit on CCl4 induced-hepatotoxicity". J. Ethnopharmacol.; 15; 96(3): 529-535.

22. Hassan, S.H.M.; Abu-Ghadeer A.R.M.; Osman, S.A.A. and Roushdy, H.M. (1994): "Possible curative role of the antipsychotic drug : Fluphenazine: against
Post-irradiation injury in rats". Egypt. J. Rad. Sci. Applic.; 7(2): 181- 200.

23. Jiangui, J. and Sun, G. (1993): "Effect of fractionated gamma-irradiation on SOD activity and lipoperoxide count in liver and kidney tissues of adolescent mice". J. Radiat. Res. and Radiat. Process; 11(2): $104-106$.

24. John, D. and Bauer, M. (1982): "Clinical laboratory methods for the determination of serum alkaline phosphatase". C.V. Mosby Co., USA, 9th ed.: 580-581.

25. Kamat, J.P.; Boloor, K.K.; Devasagayam, T.P.;, Jayashree, B. and Kesavan, P.C. (2000): "Differential modification by caffeine of oxygen-dependent and independent effects of gamma-irradiation on rat liver mitochondria". Int. J. Radiat. Biol.; 76(9): 1281-1288.

26. Kergonou, J. F.; Thiriot, C.; Braquet, M.; Ducouss, R. and Rocquet, G. (1986): "Influence of whole body gamma-irradiation upon rat erythrocyte: Lipid peroxidation and osomotic fragility". Biochemie. (Paris), 68(2): 311-318.

27. Kus, I.; Colakoglu, N.; Pekmez, H.; Seckin, D.; Ogeturk, M. and Sarsilmaz, M. (2004): "Protective effects of caffeic acid phenethyl ester (CAPE) on carbontetrachloride- induced hepatotoxicity in rats". Acta Histochem.; 106(4): 289-297.

28. Lee K.J.; Terada, K.; Oyadomari, S.; Inomata, Y.; Mori, M. and Gotoh, T. (2004): "Induction of molecular chaperones in carbon-tetrachloride-treated rat liver: implications in protection against liver damage". Cell Stress Chaperones., 9(1): 5868.

29. Luo, Y.J.; Yu, J.P.; Shi, Z.H. and Wang, L. (2004): "Ginkgo biloba extract reverses CCl4-induced liver fibrosis in rats". World J.Gastroenterol.;10(7):1037-1042.

30. Martin, A. and Harbison.A. S. (1986): In "Introduction to Radiation Protection", 3rd ed. Chapman and Hall Ltd., London, 37.

31. Masquelier, J. A. (1996): "Lifetime devoted to OPC and Pycnogenols". Alfa Omega Editrice, Pub, 8(3):155-164.

32. Mohiuddin, M.; Chen, E. and Ahmad, A. (1996): "Combined liver radiation and chemotherapy for polliation for hepatic metastasis from colorectal cancer”. J. Clin. Oncol., 14: 722.

33. Murray, M. and Pizzorno, J. (1999): "Procyanidolic oligomers". In: Murray M, Pizzorno J, eds. The Textbook of Natural Medicine. 2nd ed. London: Churchill Livingston; 899-902. 
34. NCI "National Cancer Institute" (1985): Division of Cancer Etiology. "Monograph on Human Exposure to Chemicals in the Workplace": CC14. Technical Report No. 84-1123.Bethesda, MD: Department of Health and Human Services.

35. Nunia, V. and Goyal, P.K. (2004): "Prevention of gamma radiation induced anemia in mice by diltiazem". J. Rad.. Res. 45(1): 11-17.

36. Piyachaturawt, P.; Kingkaeohoi, S. and Toskulkao C. (1995): "Potentiation of CCl4 hepatotoxicity by piperine". Drug. Chem. Toxicol.; 18(4): 333- 344.

37. Poli, G.; Cheeseman, K.H.; Biasi, F.; Chiarpotto, E.; Dianzani, M.U.; Esterbauer, H. and Slater, T.F. (1989): "Promethazine inhibits the formation of aldehydic products of lipid peroxidation but not covalent binding resulting from the exposure of rat liver fractions to CC14”. Biochem. J.; 264(2):527532.

38. Ray, S.D.; Wong, V.; Rinkovsky, A.; Bagchi, M.; Raje, R.R. and Bagchi, D. (2000): "Unique organo-protective properties of a novel IH636 grape seed proanthocyanidin extract on cadmium chlorideinduced nephrotoxicity, dimethylnitrosamine (DMN)-induced splenotoxicity and mocap-induced neurotoxicity in mice”. Res. Commun. Mol. Pathol. Pharmacol.; 107 (1-2):105-128.

39. Reitman, S. and Frankel, S. (1957): "A colorimetric method of the determination of serum glutamic oxaloacetic and glutamic pyruvic transaminases. Am. J. Clin. Pathol., 28: 56.

40. Shukla, S.; Bhadauria, M. and Jadon, A. (2004): "Effect of propolis extract on acute CCl4 induced hepatotoxicity". Indian J. Exp. Biol.; 42 (10): 993-997.

41. Slater, T.F. (1982): "Free radicals as reactive intermediates in injury". In R Synder, DV Parke, JJ Kocsis, DJ Jollow, GG Gebson, CM Witmer, Eds. Biological reactive interm ediates II: Chemical mechanisms and biological effects. New York: Plenum. Press. 575-589.

42. Snedecor, W.G. and Cochran, G.W. (1980): "Statistical methods." 7th edition, Iowa State University Press; Ames, Iowa.

43. Sugisawa, A.; Inoue, S. and Umegaki, K. (2004): "Grape seed extract prevents
H2O2-induced chromosomal damage in human lymphoblastoid cells". J. Biol. Pharm. Bull. 27(9):1459-1461.

44. Szasz, G. (1969): "A kinetic photometric method for serum $\gamma$-glutamyl transpeptidase. Clin. Chem.; 22: 124-136.

45. Valcheva, K.S.; Borisova, P.; Galunska, B.; Krasnaliev, I.; and Belcheva, A. (2004): "Hepatoprotective effect of the natural fruit juice from Aronia melanocarpa on CCl4-induced acute liver damage in rats. Exp. Toxicol. Pathol.; 56(3):195-201.

46. Veluri R., Singh R.P., Liu Z, Thompson J.A., Agarwal R., and Agarwal C. (2006): Fractionation of grape seed extract and identification of gallic acid as one of the major active constituents causing growth inhibition and apoptotic death of DU145 human prostate carcinoma cells. Carcinogenesis. 10; 1093-7.

47. Wang, S.; Tang, D.; Zhao, Y.; Gao, G. and Hu, L. (1999): "The effect of pycnogenol on the microcirculation, platelet function and ischemic myocardium in patients with coronary artery diseases". Eur. Bull. Drug Res.; 7: 19-25.

48. Weiss, J.F. and Landauer, M.R. (2003): "Protection against ionizing radiation by antioxidant nutrients and phytochemicals". Toxicology, 189:(1-2):1-20.

49. Yamakoshi, J.; Saito, M.; Kataoka, S. and Kikuchi, M. (2002): "Safety evaluation of proanthocyanidin-rich extract from grape seeds". Food Chem. Toxicol.; 40: 599-607.

50. Yan, T. L.; Guei, J.W.; Jen, H.C. and Han, C.L. (2003): "Long-term administration of Salvia miltiorrhiza ameliorates CCl4-induced hepatic fibrosis in rats." J. Pharm. and Pharmacol.;55(11):1561-1566.

51. Yasuda M.; Okabe, T.; Itoh, J.; Takekoshi, S.; Hasegawa, H.; Nagata, H.; Osamura, R. and Watanabe, $K$. (2000): "Differentiation of necrotic cell death with or without lysosomal activation": Application of acute liver Injury models induced by carbon- tetrachloride and dimethylnitrosamine (DMN). J. Histochem. Cytochem.; 48, 1331-1340.

52. Yoshioka, T.; Kawada, K.; Shimada, T. and Mori, M. (1979): "Lipid peroxidation in maternal and cord blood and protective mechanism against activated oxygen toxicity in the blood". Am. J. Obstet. Gynecol.; 135: 372-376. 


\section{التأثير الوقائى لمستخلص بذور العنب للحماية من التأثيرات السمية لرابع

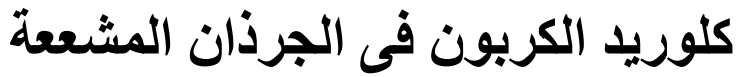

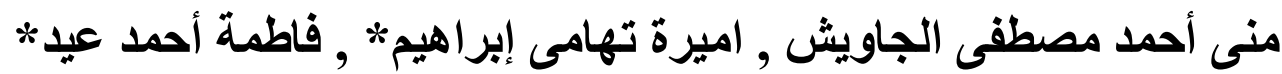

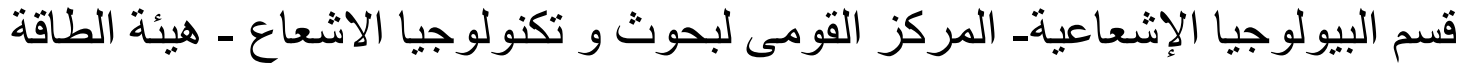

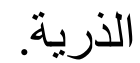

قسم علم الحيوان - كلية العلوم - جامعة الاز هر -فرع البنات

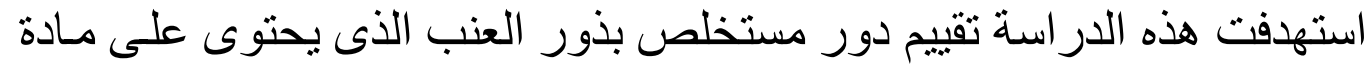

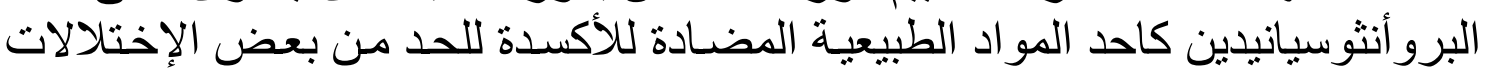

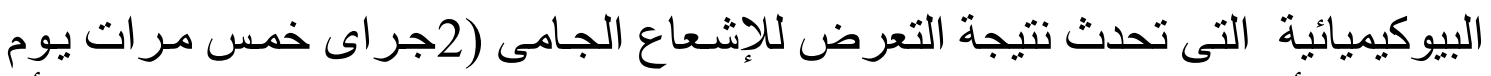

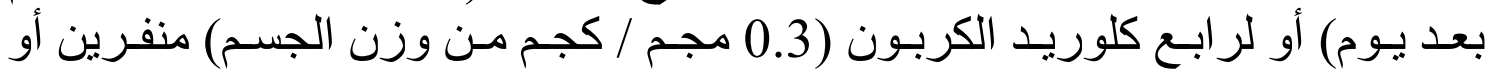

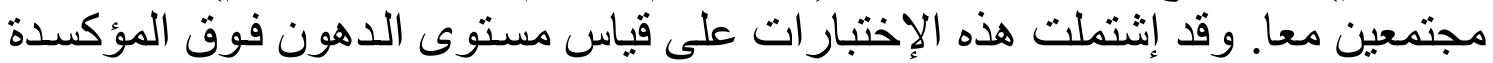

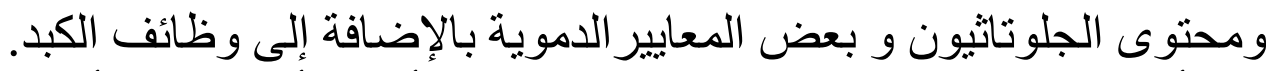

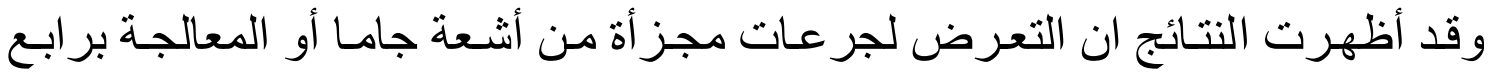

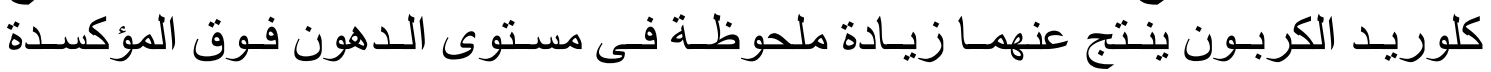

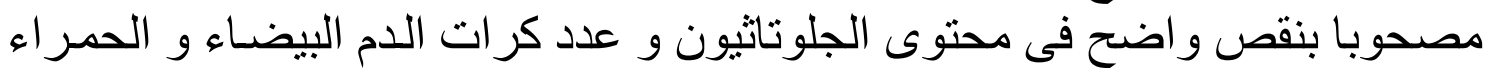

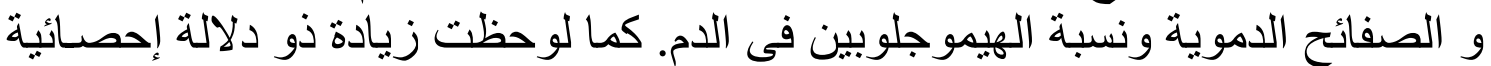

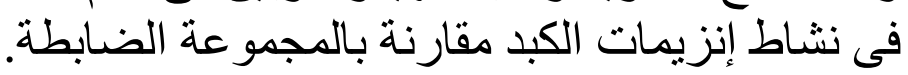

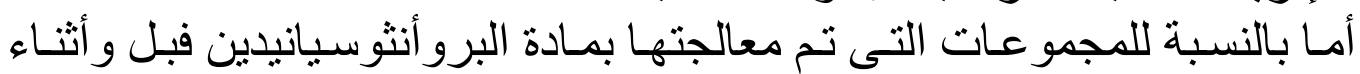

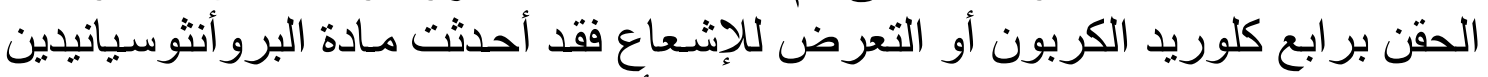

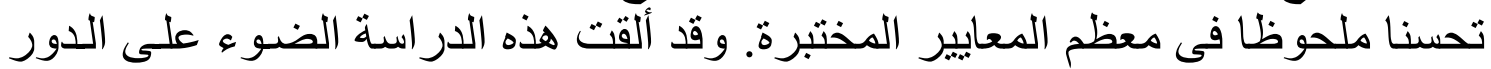

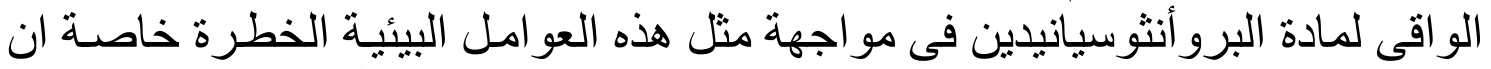

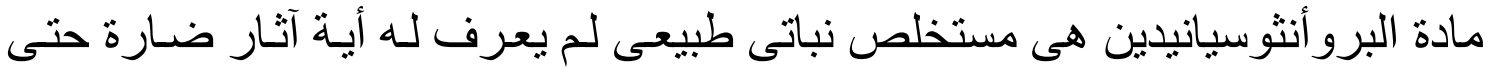

